\title{
Critical Readings of The Salesman in Iran
}

\author{
Akram Jamshidi*, Shahab Esfandiary**
}

\begin{abstract}
*Tehran University of Art, Iran
\end{abstract}
**Tehran University of Art, Iran

Abstract

\begin{abstract}
Asghar Farhadi's cinema has found a worldwide audience in recent years, and most of his movies have been globally celebrated. His most recent movie The Salesman, however, has had a dialectical existence in his own homeland. The nature of this controversy reveals up a number of dominant social issues in contemporary Iran. Accordingly, Iranian could be divided into supporters and critics of Farhadi's The Salesman. The former believe that it is about social problems and in association with Farhadi's cinema. The latter see it as his attempt for international celebration even to the point of dishonoring his homeland. This essay offers two contrasting readings of Asghar Farhadi's The Salesman by the Iranian film reviewers and critics. Data collection includes texts which were taken from the most leading cinematic publications, websites and TV shows.
\end{abstract}

Keywords: The Salesman, Asghar Farhadi, Critical reading, Iran, Culture

\section{Introduction}

One important issue in regard to art sociology is the proliferation of the interpretations on a work of art. This problematic is due to the assumption that the media content is always polysemic, or open to interpretation. (Morley, 1993). Therefore, a significant question raises, which is how people make readings of cultural forms and perceive the ideological messages. Stuart Hall (1980) has distinguished encoding / decoding theoretical model drawing concentration upon how art is received, consumed and used by people who experience it. He believes there are four primary ways of decoding a cultural text: (1). the dominant - hegemonic reading which takes the preferred reading that is meant by the author, (2). the oppositional reading which shifts the dominant ideology to an oppositional discourse, (3). the negotiated reading which maintains the connection between the ideological and the oppositional readings, and (4). the aberrant reading which indicate how a message can be interpreted differently from what it meant.

The present study offers two contrasting readings of Asghar Farhadi's The Salesman by the Iranian film reviewers and critics. This film has been selected for the following reasons: (1) It was considerably successful at the box office and it broke the record of audience at its first night release ; (2) It achieved too much praise at Cannes 2016 leading to the best screenplay and the best actor awards; (3) It has the common theme of Farhadi's cinematic career that is Iranian modern society breaking up with its traditions; and (4) It might be identified as a social event rather than a mere work of art since a huge amount of review and attention has been dedicated to the movie. Furthermore, The Salesman has been the subject of many clashes though it was officially entered into the Oscars 2017 for the best foreign film category and finally ended up in the second Oscar for Farhadi as 
well as Iranian Cinema. The nature of these conflicts makes out a number of severe social issues in contemporary Iranian society. The basic thesis of this study is that the experience of viewing a film would determine critical engagement with the dominant social issues.

\section{Review of the Related Literature}

Reading cultural texts has been a subject of interest for many researchers in regard to communication studies. Norman K. Denzin (1989) assumes that "Films, Newspapers, Popular music, published social science articles, art exhibits, soap operas, and romance novels all regularly record and speak to everyday life in modern society (P.37). In his study, Reading Tender Mercies: Two Interpretations, he argued how a Hollywood film, Tender Mercies (1983), represents and speaks to the issue of alcoholism and alcoholic families in American society. His basic thesis is that "all representation of cultural experience are ideological and hence must be read for the multiple meanings that are contained within their texts (P.38). He points out that "the experience of reviewing a film cannot be reduce to causes and effects, but must rather be studied in terms of the fields of experience a film makes available to the viewer (P.37). Denzin provides a methodology for conducting studies of cultural texts.

Regarding Iranian Cinema, Hamid Dabashi presented contrasting readings of Abbas Kiarostami's Through the Olive Trees (1994) in his study; Re-Reading Reality: Kiarostami's Through the Olive Trees and the Cultural Politics of a Post-revolutionary Aesthetics. He argues "that Kiarostami's cinema has found a global audience, and that Iranians respond with furious sincerity for or against his vision of things, are all integral to the cultural consequences of that cinematic vision" which "has sought to reread a reality we have grown to accustomed to reading in old and tired ways" (P.64). Dabashi points out that Kiarostami's presence in his homeland is controversial. The earthquake of 1991 in northern Iran and the film that Kiarostami made in relation to it constitute perhaps the most central battlefield in which his cinematic vision is being questioned. While his admirers join European and American critics, his detractors consider him a talentless pseudo-intellectual who dismissed the tragic depth of the earthquake in northern Iran.

\section{Methodology}

In the current study, an analysis of critical readings of Farhadi's The Salesman in Iran will be provided. The data consisted of almost 50 texts which were taken from the most significant cinematic magazines in Iran and in Persian language; including Film Monthly, 24, Donyaye Tasvir [Picture World], Naghde Cinema [Movie Review], and Filmnegar [Screenplay] and Filmkhaneh [Film House]. Moreover, the growth of the online media resulted in a large amount of critical readings and reviews. Accordingly, a considerable part of this study is the result of online materials such as Cinematic weblogs like Caffecinema or personal weblogs of the prominent Iranian critics. 
The British Cultural Studies approach represented by Stuart Hall, which is interpretive and interested in the intentions or meanings of individuals, is the method to decipher the meaning in this article.

In addition, this article will follow the method of Norman K Denzin (1989) who offers using narrative as data. It has to be mentioned that he used the term Realist reading to subsume Stuart Hall's hegemonic and negotiated readings, and the term Subversive reading to refer his oppositional reading. The followings outline the general procedure:

- Obtaining a record of cultural text (a film, a novel . . .) and subjecting that document to multiple readings.

- Defining the narrative story themes that are present in the text.

- Collecting the realist, hegemonic interpretations of the text.

- Interpreting those readings in terms of their dominant ideological meanings.

- Developing a subversive reading of the text.

- Contrasting the subversive, oppositional readings to the realist interpretations.

\section{The Narrative}

Emad [Shahab Hosseini] is a young teacher who teaches literature and lives in Tehran with his wife Rana [Taraneh Alidousti]. They work with a non- professional theatre group as well. They take the leading roles, Willy and Linda, of the well-known play by American modern playwright Arthur Miller. Every evening they participate in the rehearsals. They also have to leave their house because of the unauthorized excavation next to their building. They look for a new place to live. Babak [Babak Karimi], their friend and a member of the same theatre group offers them to take his friend's house on the top of a high building. Emad and Rana welcome the idea but there is a major problem; the former tenant, a young woman called Ahoo, has not taken out her appliances and furniture. She has locked one of the bedrooms occupied with her belongings. Emad and Rana move to the new place considering she would move out soon. But Ahoo does not appear. In addition, they gradually know that Ahoo is a notorious woman in the building and most of neighbors feel unsatisfied with strangers commuting to her house. Meanwhile Emad and Rana should start casting on the stage. At the same time, the Ministry of Culture and Islamic Guidance [Vezarate Farhang O Ershade Eslami], responsible for the cultural texts' censorship in Iran, announces that some part of the play should be extracted. Emad is going to discuss the issue, so Rana is going back home alone. She is going to take a shower and get the entrance door open carelessly considering it is Emad ringing the bell, but a stranger enters. The man invades her in the bathroom and runs away. The neighbors take Rana who is seriously injured to the clinic. When Emad comes home there are various cues everywhere to lead him to the invader. He starts looking for him like a detective. But his search annoys Rana and makes their peaceful marital status become unsteady. 


\section{A Realist Interpretation}

According to Denzin (1989) a traditional realist reading seeks to discover how a film speaks to the universal features of the human condition. It treats film as a window into the world. Therefore, a realist reading of The Salesman as a social film determines the following:

- The film is about a young couple in the city of Tehran who are struggling with the case of a sexual assault.

- The young woman would prefer not to report to the police and shows up signs of a trauma.

- The young man starts a personal investigation to find the aggressor though it bothers his wife.

- Friends and neighbors feel curious and express their comments and feelings about the issue.

- The climax in the film is when the identity of the aggressor is revealed.

- The key moment is when the woman is in contrast with her husband in regard to dishonoring the offender, a typically honored Iranian old man, in the presence of his own family.

- The spectator stands at the difficult position of having to judge.

\section{Re-reading The Salesman}

Asghar Farhadi's cinematic career has the reputation of evoking cinematic ethics. In fact, his films express ethical ideas. The Salesman also goes on to this steady theme of Farhadi's works. A dialectical reading of the film reveals how the experience of viewing a film would connect to critical social and cultural issues. The underlying debates over this film are Justice and Ethics, Privacy, Women's issues, culture and politics.

\section{Justice and Ethics}

Film Monthly the leading cinematic magazine in Iran provided a special dossier for The Salesman. The majority of critics who wrote for the dossier consider The Salesman in accordance with Farhadi's cinematic career. Shahram Jafari-nezhad believes that Farhadi's protagonist has consistently been put at the junctures of morals and justice, though the significance of The Salesman is the confrontation of the individual ethics in contrast with the social morals. On the side of this perspective some of the reviews refer back to Qeysar [Behrouz Vossuoghi], the protagonist of a movie (1969) with the same title by Mas'ud Kimiai a well-known filmmaker of the Iranian Cinema's new wave in 1960s. Qeysar decides to take revenge to do the justice over the violence against his sister (Qoreyshi, 2016). But Emad is the representative of the society's intellectuals. He is a cultural character. He teaches literature. He introduces literary books to his students which would not be certified with the current educational system which is heavily under the influence of the ideological themes of the ruling class. Therefore, his reaction to the same issue should be different from Qeysar. However, he finally decides to do the justice by 
himself rather than going to the police. Accordingly, the final sequence of the movie appears to be dialectical and leads to some argumentative concepts such as a "failure to living up the gendered notions of honor" for a typical Iranian man. Mas'ud Farasati argues that Farhadi's perspective offers weighting for the rapist not for the victim. He explains:

In the final sequence the camera is looking down the old man (high angle shot) and Emad is standing over him. This means the invader is oppressed and the victim is oppressor. .. Emad's slapping on the man's face makes the audience clap for the movie in Iran and bring Farhadi awards in international festivals because it is a symbol of Iranians' violence and brutality. ${ }^{1}$

\section{Miller's Death of a Salesman}

The staged performance of Miller's Death of a Salesman gives rise to the controversy over the character of Willy Loman. In the first instance it is discussed who might be Willy's corresponding character in the movie? Emad or the old man [Farid Sajadi Hosseini]? But some of the critics believe that there is no real connection between the movie and Miller's text. Saeid Ghohtbizadeh in the weekly Cinematic TV show of Cinema 7 suggests that there is no thematic connection between the movie and Death of a Salesman:

What is the main idea of the film? Gradual metamorphosis? The procedure through which an honorable man in the fabulous opening scene become the teacher we will see in the class? Therefore there could be any other play more relevant to the theme. I haven't seen any common motif between the Salesmen and the play except for the socks! ${ }^{2}$

In reply to the question "What common aspects have you seen between your screenplay and Miller's text?" Farhadi asserts:

The most significant feature of the play made me interested in was the fact that although it is a familial drama you might also feel the outside world of their house, the American society of the time (late 1950s) . . . Death of a Salesman is about the advent of Capitalism in the United States. . . Iran is crucially different from the American society of the time. Iran is a special country with a dominant ideological base of the ruling class. But we have something in common. We are changing with the same rapidity. Whether in the appearance of the society and physical view of the cities or in the state of the social relationships.

Naghde Cinema [Movie Review] is the official cinematic publication of Hoze Honari [Islamic Development Organization]. It also provided a special dossier for the movie, although the reviews mostly do not match by the

\footnotetext{
${ }^{1}$ Face to face conversation between Mas'ud Farasati and Dr. Shahab Esfandiary in weekly TV show of Cinema7, 2016/9/23

${ }^{2}$ Face to face conversation between Mas'ud Farasati and Saeid Ghotbizadeh in weekly TV show of Cinema7, 2016/9/9
} 
almost realist reviews in Film Monthly Magazine. The central clash is over the Miller's Death of a Salesman as well. Sajjad Mehregan analyzes the movie from a Foucauldian point of view:

Like Foucault, he (Farhadi) is a critic of modernity and the most significant (similarity) is that he does not speak about power and politics straightforwardly. There is no doubt that Foucault means the government, power and Politics when he describes The History of Madness or Sexuality . . . This power has both external signification, including sovereign power, and internal signification, including individual functions in the form of a chain. These chains whether imposed to body from social sovereign or conducted by the internal discipline of individuals, has one significant measure which is Censorship . . . (in The Salesman) all the events happen the night when Emad is going to discuss the issue of censorship.

Fatemeh Torkashvand ${ }^{3}$ sees The Salesman as Farhadi's subversive reading of a play which is possessed of a reputation against Capitalism. She explains that Miller's Death of a Salesman concentrates on the spiritual death of Willy under the pressure of a lifestyle forced by Capitalism. In Miller's View, Capitalism is responsible for all Willy's misfortune. On one hand it provides a simple salesman with heroic dreams and hedonistic view of life which has been displayed as a natural low, on the other hand throws him away like an industrial commodity after being used, while his dreams remain as disgusting illusions and nostalgia. But among all these issues which are undeniably related to ontological and anthropological principles of Imperialism, Farhadi chose to focus on the pedagogic implications of the text.

Subject to the screening of a French movie with the same title of The Salesman, Farhadi screens his movie with the title of le Client in France. Therefore, the title appears to be questionable for the opponents. They believe if it modifies the story how it would be possible to call the movie The Client as well, and where the idea of the title comes from. This query gives rise to questions by these critics, such as "Who is the salesman?" or "What is on sale?" or "Who is the client then?" and "Why it does not basically make any difference which one to take as the title?" In the same issue of Naghde Cinema [Movie Critic], Meysam Amiri and Sajjad Nowroozi accuse Farhadi of denigrating his national and cultural identity:

Who is the Salesman? A salesman is a person who sells something. If we are not looking for the Salesman among the characters, then Farhadi himself would be the Salesman. The filmmaker is sympathetic with the rapist. In the final part of the movie he looks for the viewer's pity - not kindness- and asks them to stand for the miserable old man rather than Emad by humiliating all his characters. It is the filmmaker who depicts Iran in a shaky situation which is going to collapse. The Salesman denigrates Iran and Iranians as far as possible, by illustrating a regressive and naive community of Iranians who are frequently

\footnotetext{
${ }^{3}$ Fatemeh Torkashvand is a young Iranian journalist. She mostly works with right- oriented publications and News agencies.
} 
deceived and not able to come out of this filth . . . His movie wins among westerners despite the technical gaffes. Farhadi himself is the Salesman.

Houshang Golmakani the editor-in-chief of Film Monthly whose review is fundamentally supportive of The Salesman explains that there are many examples of films in the cinema of world with no direct implication in the title, specifically in the last two decades. He asserts that a filmmaker like Asghar Farhadi certainly attains a perception for his choices, though it might not match with the audience's choice.

\section{Privacy}

In regard to the social issues of the film, Houshang Golmakani assumes privacy a critical issue of modern Iran. He describes the situation as:

The film initiates with an insecure situation; the building is at the risk of a collapse because of the illegal excavation nearby. But the threat has been existing before, if not to the point of collapsing. There is a metal security door in front of the couple's apartment similar to many others in the city of Tehran . . . Another kind of insecurity exists within the characters; Babak who is a bachelor with an obscure past is one of the former tenant's clients, Sanam the divorced woman who is identical with Ahoo (her little son goes on drawing on the wall of the same house) and the woman in taxi who is complaining to Emad. This subject would end up in the idea of blackening which is (Iranian) politics and their followers' favorite term being used to intimidate filmmakers concerning social issues. Actually, there have been many crimes announced by the officials, like robberies, sexual assaults and street violence and all of them are examples of this insecurity. . . In contrast to Hollywood thrillers that a catharsis is present as we come to the end of the movie, there is not any sort of catharsis for the spectator and his anxiety is even worsened by observing such a person as a violator; knowing that nobody could be trusted anymore. And this is the deepest sense of insecurity.

Dr. Shahab Esfandiary, critical theory and film studies professor, in a hit live debate TV show, criticized Mas'ud Farasati and Behrouz Afkhami, Iranian filmmaker, for the outlying implication they back by calling the movie a "failure to living up the gendered notions of honor". He points out:

It is difficult for a woman to talk about the experience of being assaulted. Even in Western countries there might be numerous cases of violence against women while few people might go to the police, therefore it might be even more difficult here in Iran . . . The movie also goes on to the steady theme of Farhadi's works. His movies are about the difficult 


\begin{abstract}
position of having to judge, not relativism which Mas'ud Farasati claims. It is a particular moral situation expressing the idea of respecting others 'privacy. ${ }^{4}$
\end{abstract}

\title{
Women
}

The salesman is the story of women, in particular, Rana a young actress seemingly representative of new generation of women in Iran who are educated, socially active and having a voice. Seeing that Rana is generally passive through the story, Asghar Farhadi has been accused of ignoring the woman part or, doing with the same patriarchal bias existing in the Iranian society. Marzieh Rasouli ${ }^{5}$ Iranian Journalist and social activist in talking to Taraneh Alidoosti asserts that women are passive in Farhadi's works and in this film Farhadi takes the man's perspective. In reply, Taraneh Alidousti confirms that the movie's perspective is a masculine view and believes that Emad is himself a victim of this male - dominance social situation:

I think this is the first time that Farhadi is thoroughly aware of the crucial situation of his female characters. I see it through the sequence that Sanam [Mina Sadati] complains about her co- actor's laugh which is about her role as a prostitute . . . (I think) passiveness of Rana for the sake of contemplation about what should be done is worthier than Emad's violence.

On the other hand, Fatemeh Torkashvand in a harsh condemnation of the film's view about women writes:

In The Salesman a woman, Rana, [Taraneh Alidousti] has been assaulted and the issue is no body's business except Rana, in Farhadi's view. Her husband must take her choice a priority, whether to forgive or to ignore or going to police or looking for the aggressor or making any other decision. But as noted by Alidousti in the movie conference, Emad [Shahab Hosseini] goes too far and makes it his personal issue for being violent and taking revenge.

\section{Contradictions in the text}

The main situation of The Salesman is apparently similar to a screenplay written by Bahram Beyzae'i; Haghayeghi darbareye Leyla Dokhtare Edris [Facts about Leyla the Daughter of Edris] in which Leyla, the main character, is considered the same as the former tenant of her new house. However, Farhadi's screenplay mostly is connected

\footnotetext{
${ }^{4}$ Weekly TV show of Cinema 7, (2016/09/23).

${ }^{5}$ Marzieh Rasouli is a journalist who writes about culture and art and works with reformist newspapers. She was arrested in 2012 accused of acting against national security. She was released some months later.
} 
to the movie Gav ${ }^{6}$ (The Cow) by Dariush Mehrjui which is an adaptation of Azadaran- e Bayal[The Mourners of Bayal] by Iranian well known ethnographic and fiction writer Ghulam- Hussein Sā'edi. In fact, a dialogue between Emad and his student is the main cause of conflict. The student asks him "how a person might become a cow" and Emad responds: "step by step". Many critics take this dialogue as a cliché has been imposed to the story, though it is not the consequence of a real situation that could be imagined in a high school class in Iran. A number of critical issues dwell on the fact that what has really happened in the bathroom? Is it an objective sexual assault or just a kind of harassment? Many critics have discussed that the physical state of the old man could not allow him to be a rapist. But Farhadi does not show the bathroom sequence in order to let his audience stay with a range of interpretations behind. Mas'ud Farasati contradicts this view in a review in his weblog:

The main question for the spectator of this loose film is that: Has a sexual assault occurred? In the film conference, Farhadi points out definitely: "It has not happened", while the movie is more likely to show it has been occurred. Whereas it is not due to its mise - en - scène, which it lacks in fact, but due to some dialogues, one by its miserable rapist: "I was tempted" and the other one by its doleful victim: "I wish I had died". Farhadi in another interview, with a Hitchcock- like joking gesture, not really matching with him, says:" I haven't been in the bathroom; I don't know what has happened." What are these contradictions if not bearing witness to frustration?

Furthermore, most reviewers draw specific attention to Babak and Emad's dialogue on the top of the new house. Emad wishes that it would be possible "to destroy the entire city of Tehran and rebuild it". Babak responds "it had been done before and became almost what it is now". Farhadi's critics see this dialogue as his political manifest addressing the country's rulers.

\section{Conclusion}

The present study provides two contrasting views on Asghar Farhadi's recent movie The Salesman. Accordingly, data collection includes texts which were taken from the most leading cinematic publications, websites and TV shows. Farhadi's cinematic vision associates with social problems. In fact, his films highlight critical issues existing in contemporary Iran. Therefore, his movies has found a large amount of interpretation inside the country while highly celebrated outside Iran. The Salesman has had the most controversial presence of Farhadi's cinema in Iran. The nature of this dispute reveals up a number of dominant social issues in contemporary Iran. The most important is that Iranian society is a polarized society. Actually, the movie's screening reflects on the contradictions within the Iranian society. In this case study, the reviewers who has made a reading of the movie could be divided to the supporters and opponents of the film. The former sought to interpret the movie in relation

${ }^{6}$ The Cow is the first Iranian full length feature film which was screened in an international festival at Venice in 1971. It received the Critic's Award. 
to Farhadi's cinematic style. They stand for Farhadi's vision about critical social issues such as ethics, women's status or modernity in contrast to tradition. The latter focus on the idea of denigration of Iranians and accuse him of a number of claims, even of being a traitor. They believe that the film portrays Iran in an unsteady and shaky situation by narrating an occasional case of crime. Moreover, the filmmaker's mise - en - scène makes the spectator feel sympathetic with the rapist. Farhadi's critics adapt a prospect against some part of the film's dialogues regarding as clichés. Therefore, they suppose that Farhadi has actually recourse to off screen voice to present his manifest and there is no real narration but detached concepts which are welcomed at Cannes such as the case of sexual assault and violation against women.

\section{References:}

Amiri, M., \& Nowroozi, S. (2016, October). Farhadie Foroushande [Farhadi, the Salesman]. Movie review, 18 (73), 41-47.

Dabashi, H. (1995). Re-reading reality: Kiarostami's through the Olive trees and the cultural politics of a postrevolutionary aesthetics. Critique: Critical Middle Eastern Studies, 7(4), 63-89. http://dx.doi.org/10.1080/10669929508720075

Denzin, N. K. (1989). Reading Tender Mercies: Two Interpretations. The Sociological Quarterly, 30(1), 37-57. http://dx.doi.orq/10.1111/i.1533-8525.1989.tb01510.x

Farasati, M. (2016, September). Excusez Moi [Weblog post]. Retrieved from http://massoudfarassati.com/showpage.php?pid=11\&cid=12/2016/01/10

Golmakani, H. (2016, September). Khane-am Abri Ast [My house is cloudy]. Film Monthly, 34(514), 85-87.

Hall, S. (1980). Culture, Media, Languages. London, England: Hutchinson.

Jafari-nezhad, S. (2016, September). Edalat va Akhlagh [Justice and Ethics]. Film Monthly, 34(514), 68-69.

Mehrabi, M. (2016, September). Interview with Asghar Farhadi. Film Monthly, 34(514), 88-97.

Mehregan, S. (2016, October). Yek Esfahani Dar Paris [A man from Isfahan in Paris]. Movie review, 18 (73), 3031.

Morley, D. (1993). Active Audience Theory: Pendulums and pitfalls. Journal of Communication, 43(4), 13-19. http://dx.doi.org/10.1111/i.1460-2466.1993.tb01299.x

Qoreyshi, A. (2016, September). Vaghti Edalate Fardi Dar Tazad Ba Edalate Ejtemaei Gharar Migirad [When the individual justice is in conflict with the social justice] [Weblog post]. Retrieved from http://www.caffecinema.com/new/index.php/critic/item/14571/2016/06/12

Rasouli, M. (2016, September). Interview with Taraneh Alidousti. Film Monthly, 34(514), 98-102.

Torkashvand, F. (2016, October). Maskhe Foroushande / Gave Farhadi [The Salesman's metamorphosis / Farhadi's The Cow]. Movie Review, 18(73), 38-40. 